\title{
CAMPUS PAPERLESS CONFERENCE SYSTEM - A CASE STUDY OF A NATIONAL UNIVERSITY IN CENTRAL TAIWAN
}

\author{
Tung-Shou Chen \\ National Taichung University of Science and Technology \\ No.129, Sec. 3, Sanmin Rd., North Dist., Taichung City 404, Taiwan \\ (R.O.C.) \\ tschen@nutc.edu.tw \\ Jeanne Chen \\ National Taichung University of Science and Technology \\ No.129, Sec. 3, Sanmin Rd., North Dist., Taichung City 404, Taiwan \\ (R.O.C.) \\ jeanne@nutc.edu.tw \\ Chun-Wei Chuang \\ National Taichung University of Science and Technology \\ No.129, Sec. 3, Sanmin Rd., North Dist., Taichung City 404, Taiwan \\ (R.O.C.) \\ s18013112@nutc.edu.tw
}

\section{ABSTRACT}

Meetings are an activity in everyday workforce to exchange face-to-face ideas and communications. When a meeting is held, it involves certain processes. A large number of supporting documents will be needed to support the meetings. As environmental awareness increases, the aims of this research are to reduce operating schedules and to decrease the amount of paper usage. The purpose is to develop a meeting system used to convene and conduct meetings. Currently, the existing meeting systems are focused on actions during the meeting process, and not on the whole meeting process before a meeting actually convenes. In this paper, we proposed an open source online campus paperless meeting system. The main focus of the proposed system is to provide a paperless meeting service system from the start to the end of a meeting. Experimental results showed that paper usage of the proposed method can be effectively reduced, and the operating time for meetings can also be shortened.

Keywords: Paperless Meeting, Meeting System, BigBlueButton 


\section{INTRODUCTION}

In the workforce, meetings are an activity that regularly take place, which can be time consuming and requires a large amount of paper that goes to waste after the meeting is concluded. Common types of meetings include: office meetings, group meetings, seminars, and many more ${ }^{1,2}$. Traditionally, when a meeting is held, a large amount of documents will be needed to support the meeting. The staff preparing for the meeting spends a lot of time preparing and then printing the necessary documents to be distributed to all attendees before the start of the meeting. During the meeting, incorrect information or requested changes would require time and paper to redo and reprint the documents in this respective order. The process is strenuous, time-consuming, and not cost-effective.

With the advancement of information technology, more and more people are beginning to use computers for electronic documents ${ }^{3}$. Before a meeting, the electronic document must be sent to the staff responsible for collecting and distributing these documents at the meeting. Normally, the documents for the meeting will be printed and distributed to all attendees. It is also normal to print extras in case of uninvited turn ups. However, when meeting documents were prepared incorrectly or unforeseen changes were required, the staff can only update the electronic document through a swap file or overwrite mode. This action can be completed in a short time to update the files, but is likely to cause confusion or inconsistencies. Also, the modified document will have to have to be reprinted for all attendees.

A possible solution for this problem would be to reduce operating schedule and to decrease the amount of paper needed by printing and reprinting processes when convening or conducting a meeting. However, the existing online meeting systems are focused on actions during a meeting. They are not interested in the preparation that occurs before and after a meeting.

In this paper, we will discuss the meeting processes that go through a campus and to propose an online meeting system that decreases preparation time for meetings and decreases the amount of paper used in the process. The system also includes an online conference system for convening a meeting. The proposed system is open source to build a campus paperless meeting systems for processing meetings and has meeting specifications that meet the Taiwan government announced policy of meeting specifications. The system is developed for a government-sponsored university where official meetings have to meet special meeting regulations and formats. In comparison to existing meeting systems, the proposed system can effectively reduce paper usage and operating time. 


\section{RELATED WORK}

\subsection{BigBlueButton Meeting System}

BigBlueButton $^{4}$ is an open-source meeting system developed by Dr. Bailetti of Carleton University in 2007. The first edition of BigBlueButton was later announced on Google Code. Its latest version is 8.1 and the BigBlueButton system architecture is as shown in Figure 1. As seen in the figure, the architecture provides the basis for accessibility during a meeting. Real-time application services such as video and desktop sharing to provide multimedia services are made through the Red5 streaming server. Voice services are handled by the FreeSWITCH voice switching platform.

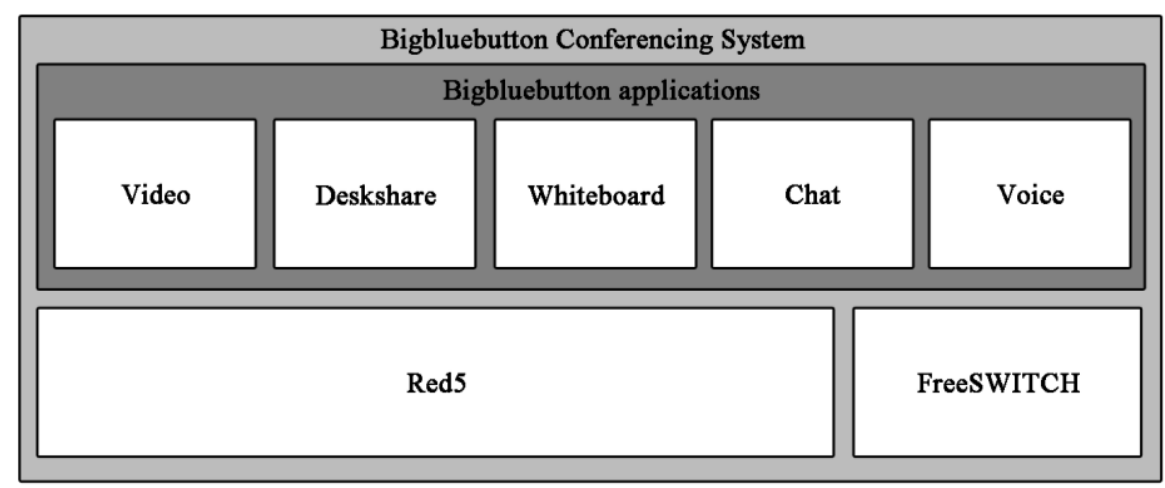

Figure 1. BigBlueButton system architecture ${ }^{4}$

The BigBlueButton server makes use of Nginx as a proxy between the client and the server. When a connection is initiated, RTMPT is invoked instead of RTMP. RTMPT is used to control the network connection time. The web and applications are handled by Tomcat with Red5. Voice application is handled by FreeSWITCH. The final step is the Ngnix RTMPT service client. The architecture for the system processes is as shown in Figure 2.

\subsection{Actual Meeting Process}

The actual meeting process is set within a national university located in central Taiwan. The meetings are normal compulsory meetings that are scheduled to take place as specified by the education bureau of the Taiwan government $^{5,6}$. 


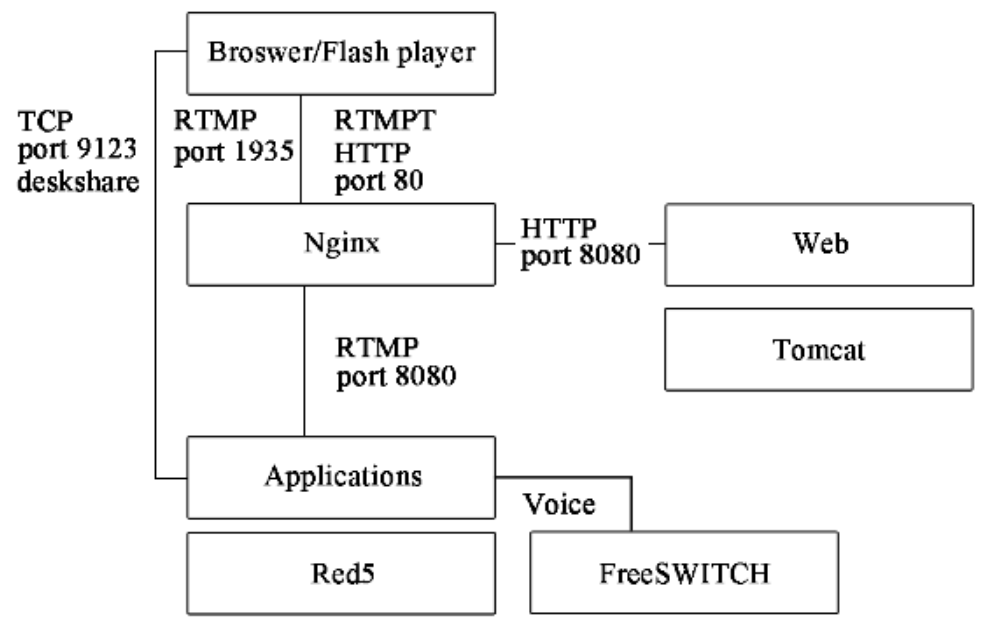

Figure 2. BigBlueButton system flow ${ }^{4}$

At the beginning of the semester, the office of secretariat plans the schedule for meetings and the representatives from the administrative units that must attend these meetings. Meeting notices are printed based on returns specifying attendance requirements for the proposed meeting. Clerks collect the report of the meeting agenda and discuss proposal profiles by phone with the various administrative units. The profiles will then be organized into meeting agendas and sent to the president for signed approvals. Participants will receive information on the meeting agenda three days ahead. When the meeting is convened, attendees signed in on attendance sheet and will be given printed meeting materials. During the meeting, recordings are done on recorders and VCRs, as well as handwritten minutes recorded on paper, to record the contents of the meeting. The recordings are on the vocal reports by various representatives and important issues being discussed and resolved during the meeting. These records were compiled into a document, and then signed by the responsible departments. Approved and completed documents will be dispatched to the various administrative units where the signed attendance sheet and documents are to be archived. The meeting process is shown in Figure 3. 


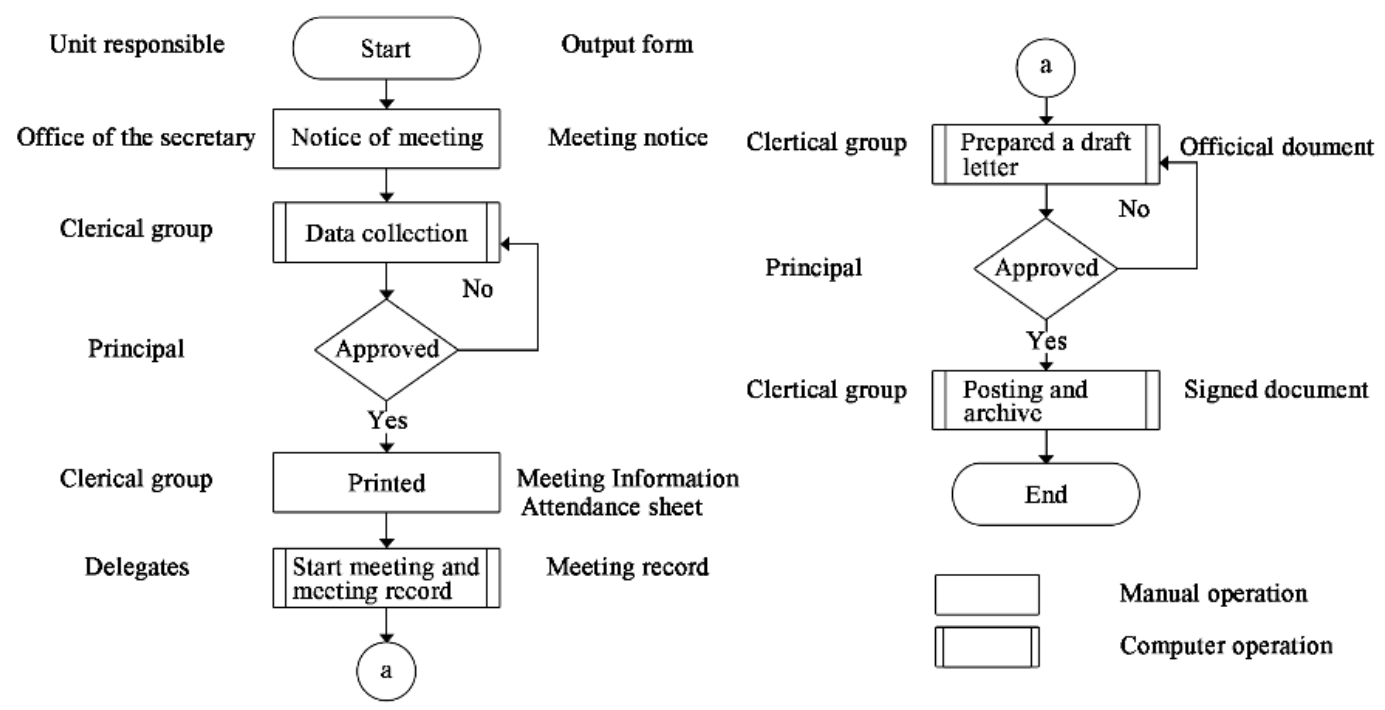

Figure 3. Flowchart of meeting ${ }^{5}$

Figure 4 shows the operating schedule used at this university. Note that for a meeting to take place, it will require notice at least 20 working days ahead. Five days before convening the meeting, the president must sign the approval agenda. Meeting documents will be printed in booklets after approval and sent to representatives for perusal. Records of meeting minutes will be sign-posted at least 10 working days ahead after the completion of the meeting.

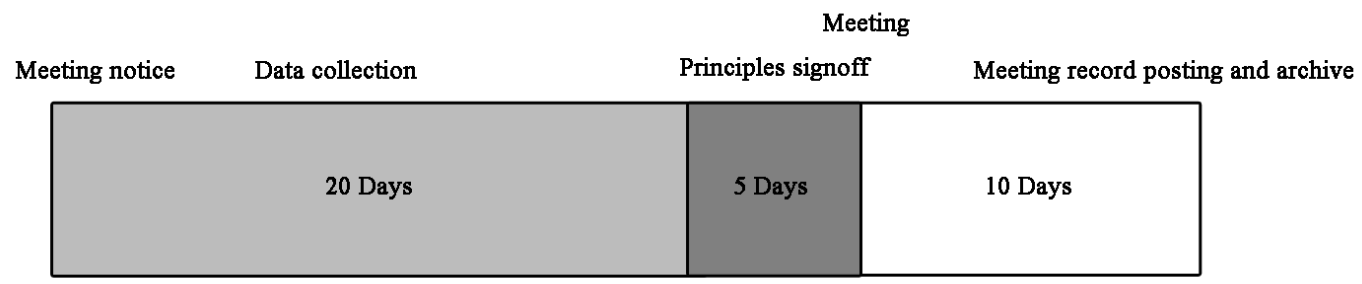

Figure 4. Meeting scheduling ${ }^{5}$

\section{METHOD}

In the current meeting or conferencing system, the basic functions and actions provided during the meeting are whiteboard and slide shows. There is no function for providing an assessment of the meeting, especially, when documents were prepared incorrectly or some changes were requested. The 
manual reprint or swapping of files to update information often delays meeting time, is prone to errors and resulted in a waste of resources.

In this study, the aim is to build a paperless meeting system that is in compliance with current board of education's policies and regulations ${ }^{7}$, the purpose of which is to shorten meeting time and reduce unnecessary wastage of resources. A paperless meeting system is developed based on agenda regulatory options. It implemented by modifying and improving the current open source BigBlueButton meeting system.

Modules are added in the new design with agenda regulatory options on BigBlueButton to help build a complete paperless meeting environment. The proposed system architecture is as shown in Figure 5. The main participants and modules involved in the system are described in the following.

Personnel: Personnel are human resource staff members who are responsible for assisting in the management of the participants in the meeting process. They are responsible for managing absentees, and for providing the different levels of access to the system based on individual official rankings in the group. The group module provides functions according to the different participants grouped for the meeting. The participants can sign in through this module.

Statements: This module generates graphs to help participants to understand the various statistics generated for the meeting. The statistics include meeting times and hours and meeting paper usage. The personnel can follow the statistics to configure the report generation time and content. The system can automatically generate reports according to the setting.

Files: This module aids the personnel to manage files for the meetings. The concerned party can update meeting information by this module. System functions include managing files maintenance and browsing by access right set by the management personnel in accordance with the ranks of officials in the meeting group.

Form: Supervisors can review and sign-off files or records for a meeting directly through the form management. They can also view the progress of document in various stages of sign-off process. In all universities in Taiwan, a call for a meeting is a process that requires sign-off from various ranking administrative officials.

Mail: This module will be based on the progress of the participants in the group and form process. Automatic notifications will be sent to relevant participants. Messages may also be sent between participants in the event of sign-off of an issue, or a query may be presented to participants without needing to wait for the chain of sign-offs to be completed. The sign-offs 
usually involve several departments which require time to complete the chain. Hence, posing queries or issue in the middle of the chain would be feasible so that problems may be rectified before reaching end of chain; thus saving processing time.

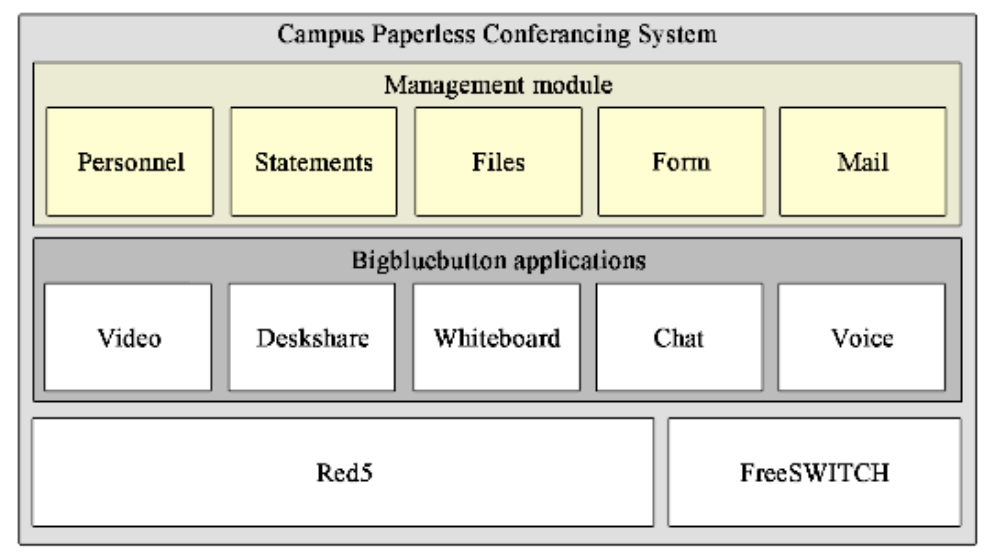

Figure 5. Proposed system architecture.

\section{EXPERIMENTAL RESULTS}

The experiment is conducted for a national university located in central Taiwan. The test is conducted on staff meetings for a particular department for operational efficiency. Paper usage is evaluated by comparing before and after using the system and with several well-known meeting systems. The number of participants is 81 . The results from the meetings are as shown in Table 1. Units of the variables in the table are pages.

Table 1. Meeting paper usage statistics in traditional meetings ${ }^{6}$

\begin{tabular}{ccccc}
\hline No & $\begin{array}{c}\text { Meeting } \\
\text { notice }(\mathrm{A})\end{array}$ & $\begin{array}{c}\text { Meeting } \\
\text { information }(\mathrm{B})\end{array}$ & $\begin{array}{c}\text { Meeting } \\
\text { record }(\mathrm{C})\end{array}$ & $\begin{array}{c}\text { Subtotal (D) } \\
\mathrm{D}=(\mathrm{A}+\mathrm{B}+\mathrm{C}) * 81\end{array}$ \\
\hline $101-1$ & 1 & 110 & 122 & 18,873 \\
$101-2$ & 1 & 43 & 48 & 7,452 \\
$101-3$ & 1 & 68 & 76 & 11,745 \\
$101-4$ & 1 & 38 & 42 & 6,561 \\
$101-5$ & 1 & 70 & 78 & 12,069 \\
Total & 5 & 329 & 366 & 56,700 \\
\hline
\end{tabular}

Meeting notice refers to notice sent to the members including actual participants. Meeting information refers to the supporting documents needed 
to support the meeting. Meeting record refers to minutes and other signed documents during the meeting. The total includes the following items: Meeting notice, Meeting Information, and Meeting record, multiplied by the number of participants. The total is the amount of paper used in the meeting.

From Table 1, we found that when a meeting was held, most paper consumption is concentrated in Meeting information and Meeting record. Therefore, managing and controlling these two meeting items will help lower paper usage.

Table 2 shows that paper usage of the proposed method is effectively reduced in comparison with existing meeting systems. In the proposed system, meeting materials are viewed online and no printed copies are handed out for all the meetings. All meetings are informed via online and recordings are done by audio and transformed to electronic files. Therefore, the proposed system saves time from not requiring menial recordings or printing

Table 2. Results from comparing with various meeting methods

\begin{tabular}{cccccc}
\hline Item & traditional & BigBlueButton & TRBS & CHT & Proposed \\
\hline Meeting notice & 405 & 405 & 405 & 0 & 0 \\
\hline $\begin{array}{c}\text { Meeting } \\
\text { information }\end{array}$ & 26,649 & 26,649 & 26,649 & 26,649 & 0 \\
\hline Meeting record & 29,646 & 29,646 & 29,646 & 0 & 0 \\
\hline
\end{tabular}

\section{CONCLUSIONS}

This paper proposed a campus paperless meeting system that exploits the open source-based meeting system. We have added modules to the agenda regulatory options on the BigBlueButton system. Moreover, the proposed system is designed to retain all the operations of the original paper user but is paperless. The paperless system is designed with split screen display so that the attendees can self-handle during the meeting. Experimental results showed that paper usage of the proposed method is effectively reduced, and the operating time of meeting is also shortened.

\section{REFERENCES}

[1] J.M. Denstadli, T.E. Julsrud, and R.J. Hjorthol, Videoconferencing as a mode of communication: A comparative study of the use of videoconferencing and Face-to-face meetings. Journal of Business and Technical Communication, 26(1), p65-91, 2012. http://dx.doi.org/10.1177/1050651911421125

[2] A.J. Berena, S. Chunwijitra, H. Okada, and H. Ueno, Shared virtual 
presentation board for E-Meeting in higher education on the WebELS platform. Human-centric Computing and Information Sciences, 3(1), p1-17, 2013. http://dx.doi.org/10.1186/2192-1962-3-6.

[3] J.M. Brusco, Trending toward paperless. AORN Journal, 94(1), p13-18, 2011. http://dx.doi.org/10.1016/j.aorn.2011.04.020.

[4] BigBlueButton System Web, BigBlueButton system flow. Retrieved on December 20, 2013, from http://docs.bigbluebutton.org/overview/architecture.html.

[5] A. Padmapriya, E-Governance: A move towards paperless administration in India. International Journal of Computer Trends and Technology, 4(3), p404-411, 2013.

[6] University Affairs Meeting Set Approach, Meeting Set Approach. Retrieved on December 20, 2013, from http://secretary.nutc.edu.tw/ezfiles/2/1002/img/195/01-06_1.pdf.

[7] J.G. Bull, and R.A. Kozak, Comparative life cycle assessments: The case of paper and digital media. Environmental Impact Assessment Review, 45, p10-18, 2014. http://dx.doi.org/10.1016/j.eiar.2013.10.001. 
